\title{
DESCARTES, HEIDEGGER, A COMPREENSÃO DE HOMEM E A QUESTÃO DO TEMPO FUTURO
}

\author{
DANTE CARVALHO TARGA ${ }^{1}$ E FABRÍCIO FONSECA MACHADO ${ }^{2}$
}

RESUMO: Neste artigo, pretendemos investigar o problema da compreensão de homem e a sua relação com o tempo, sobretudo o futuro, a partir das perspectivas de Descartes e Heidegger. Ao conceber o sujeito como pensante, René Descartes instituiu a metafísica da subjetividade e a primazia da razão para a interpretação do homem. Na sua esteira, surgiu a sociedade cientificista, altamente especializada, que corrompeu a noção de ser. Por essa concepção, o tempo não passa de uma sucessão de eventos, da ordem mensurável do movimento. Sucede, todavia, que a caracterização do tempo como mera sequência de fatos, um após o outro, encobre a possibilidade de significância do agora e afasta o homem do seu ser genuíno. Na visão de Heidegger, é preciso entender o tempo como determinante da estrutura primordial do ser e sopesar precipuamente o porvir para o desvelamento da sua mais correta hermenêutica.

PALAVRAS-CHAVE: Descartes. Heidegger. Homem. Tempo. Futuro.

\begin{abstract}
In this article, we investigate the problem of the human condition and its relationship with time, especially the future, from the perspective of Descartes and Heidegger. When designing the subject as a thinking, René Descartes established the metaphysics of subjectivity and the primacy of the reason for the interpretation of man. In its wake came the scientistic society, highly specialized, which corrupted the notion of being. For this design, the time is just a succession of events, measurable movement order. It happens, however, that the characterization of time as a mere sequence of events, one after the other, covers the possibility of the significance far and away the man of your being genuine. In Heidegger's view, one must understand the time as determining the primary structure of the primarily and weigh the future for the unveiling of its more correct hermeneutics.
\end{abstract}

KEYWORDS: Descartes. Heidegger. Human being. Time. Future.

\footnotetext{
${ }^{1}$ Professor Titular da Universidade do Sul do Estado de Santa Catarina (UNISUL-SC). Mestre em Filosofia pela Universidade Federal de Santa Catarina (UFSC). E-mail: dante.targa@unisul.br.

${ }^{2}$ Bacharel e Licenciado em Filosofia pela UNISUL e UNIASSELVI, respectivamente; Bacharel em Direito pela UFPEL-RS; Especialização em Metodologia do Ensino de Filosofia; Servidor público do estado do RS.E-mail: fabricio-machado@hotmail.com.
} 


\section{Introdução}

Ao longo da história, inúmeros filósofos tentaram problematizar a questão do tempo, contribuindo sobremaneira para o surgimento de instigantes reflexões sobre o assunto através do indagar filosófico. Falar do tempo, evidentemente, é falar também do homem, do futuro, e de todos os desdobramentos que emergem daí. O porvir intriga a humanidade, visto que o desconhecido sempre gera temor.

Neste artigo, pretendemos analisar a compreensão de homem e a questão do tempo, sobretudo o futuro, a partir das perspectivas de Descartes e Heidegger. Sobre a temporalidade, em filosofia, existem três grandes vertentes. A concepção cartesiana vinculase ao tempo enquanto medida do movimento, ao passo que a visão heideggeriana o concebe como estrutura de possibilidades. Abordaremos apenas sucintamente o terceiro ponto de vista, que o trata como movimento intuído.

A partir daí, nosso esforço será o de estabelecermos algumas relações entre ambos, principalmente contrapondo essas duas perspectivas. Tentaremos comparar tais abordagens e analisar suas consequências para o modo de ver o futuro, aquilo que somos, para onde vamos.

Assim, partiremos de duas indagações fundamentais, tendo como pano de fundo os pensamentos de Descartes e Heidegger: (a) que concepção de homem podemos deduzir de cada um desses autores? (b) qual a relação do tempo com essas concepções? Para tal empreendimento, articularemos o trabalho da seguinte maneira: (1) a concepção cartesiana de homem; (2) Heidegger e o problema do ser; (3) a questão filosófica do tempo; e (4) a compreensão de homem e a questão do tempo futuro a partir de Descartes e Heidegger.

$\mathrm{Na}$ primeira parte, iniciaremos nosso percurso pela exposição da perspectiva cartesiana de homem. René Descartes partiu da dúvida a fím de desenvolver um método matemático, aplicando-o a todas as demais áreas do saber humano. Ele empreendeu uma espécie de ceticismo, mas puramente metodológico, pois partiu da mais radical falta de certezas com o intuito de construir certezas epistemológicas inabaláveis. Ao aplicar sua metodologia às reflexões sobre filosofia primeira, estabeleceu a metafísica da subjetividade, tornando a consciência, res cogitans, uma substância, coisa pensante. Com o dualismo almacorpo, o pensador francês assentou a supremacia da razão para caracterizar a natureza 
humana. Por isso, o método cartesiano fundou as bases da sociedade moderna e o modelo cientificista predominante.

$\mathrm{Na}$ segunda parte, analisaremos a recolocação da questão primordial do ser no pensamento de Martin Heidegger. Desde a metafísica clássica os filósofos vêm contribuindo para o esquecimento do ser, porque, para o pensador alemão, eles têm se limitado a analisá-lo em seu caráter meramente atualista, vinculado ao presente. De resto, também costumamos misturar o sentido do ser com a pluralidade dos entes. Para corrigir essa analítica deturpada, é preciso, antes do mais, conceber o tempo enquanto determinante da estrutura mais fundamental do ser. O ser-tempo é estrutura de possibilidade e isso concorre decisivamente para uma nova leitura de homem.

$\mathrm{Na}$ terceira parte, será necessário examinarmos brevemente as três principais concepções filosóficas acerca do tempo. Como veremos, a primeira delas considera-o enquanto ordem mensurável do movimento e vincula-se ao conceito científico e cotidiano do tempo. A segunda trata-o como movimento intuído e envolve diretamente o conceito de consciência. $\mathrm{O}$ último ponto de vista conjectura-o à guisa de estrutura de possibilidades, dado que o reputa notadamente com o tempo futuro. O possível transforma o ser em poder-ser, abertura.

$\mathrm{Na}$ quarta parte, tentaremos correlacionar os tópicos anteriores e extrair alguns desdobramentos significativos para a existência humana. Discutiremos a compreensão de homem e o tempo futuro a partir das perspectivas de Descartes e Heidegger. Com a modernidade, o caráter objetivo das ciências naturais passou a apresentar-se como modelo exclusivo do conhecimento, o que acabou desvirtuando o homem do seu projeto verdadeiro. A concepção mecânica do tempo colaborou para a trivialização do ser, ao passo que, com a preponderância do futuro para a interpretação do agora, o homem restou concebido como estrutura de possibilidades, enquanto poder-ser.

\section{A concepção cartesiana de homem}

René Descartes (1596-1650) foi um dos filósofos mais importantes da sua época e muitas vezes é considerado o pai da filosofia moderna. Ele aceitou desafiar a dúvida presente na atmosfera cultural do seu tempo no intuito de combatê-la. Desse modo, é comum 
considerarmos o ceticismo cartesiano como puramente metodológico, temporário, porque Descartes partiu da dúvida, mas para demonstrar que a razão é superior à percepção sensível, posto que as verdades da razão são iguais às verdades matemáticas. Esforçou-se, pois, por imprimir na sua filosofia e em todas as demais áreas do saber humano a rigorosidade do método matemático.

Em Discurso do método, de 1637, o autor procurou estabelecer os fundamentos mais sólidos para construir o edifício do conhecimento. Para tanto, propôs o método matemático com o objetivo de atingir a verdade segura e o rigor do conhecimento. Segundo ele, a matemática é uma das manifestações da razão. Portanto, a ordem e o rigor, garantidos pelos números, seriam reflexos da própria essência do pensamento racional. Sendo assim, ela poderia ser aplicada a qualquer área do conhecimento humano.

O método cartesiano constitui-se de quatro regras básicas, a saber: regra da evidência, da análise, da síntese e da enumeração. Pela (1) regra da evidência, não devemos tomar por verdadeira nenhuma proposição que não seja diretamente evidente, ou seja, clara e distinta. Mas como nem sempre as ideias se nos apresentam com clareza e distinção, surge a segunda regra, a da (2) análise, que diz ser preciso dividirmos os problemas complexos em partes menores, a fim de compreendê-los melhor. Assim, temos um conjunto de reflexões dispersas, a partir das quais surge a terceira regra, a da (3) síntese, recompondo os elementos dispersos, antes separados, sintetizando-os, dos raciocínios mais simples chegando aos mais complexos. Por fim, revendo todo esse processo para garantirmos a certeza do conhecimento obtido, estamos aplicando a quarta regra, a da (4) enumeração.

O filósofo francês afirmou então que por essas quatro regras básicas conseguimos chegar ao conhecimento seguro, rigoroso:

[...] o que mais me satisfazia nesse método era o fato de que, por ele, tinha certeza de usar em tudo minha razão, se não à perfeição, ao menos o melhor que eu pudesse; ademais, sentia, ao utilizá-lo, que meu espírito se habituava pouco a pouco a conceber mais nítida e distintamente seus objetos, e que, não o havendo sujeitado a nenhuma matéria em especial, prometia a mim mesmo empregá-lo com a mesma utilidade a respeito das dificuldades das outras ciências como o fizera com as da álgebra. (DESCARTES, 2004a, p. 52)

Em sua obra Meditações de filosofia primeira, Descartes aplicou o método da dúvida, apresentado no Discurso, no desenvolvimento das suas reflexões sobre o ser e o conhecimento científico. Quer dizer, utilizou sua própria metodologia para chegar às suas 
ilações sobre filosofia primeira. É preciso ficar claro que, nele, método e metafísica são inseparáveis.

Dessa maneira, começou questionando as bases, os fundamentos de todo o conhecimento, dos níveis mais básicos até os mais complexos, passando a excluir qualquer tipo de saber sobre o qual recaísse o menor indício de dúvida. Em verdade, já na quarta parte do Discurso do método,

[...] o autor começa a colher os primeiros frutos do método. Os conhecimentos metafísicos permitem estabelecer solidamente os fundamentos do conhecimento futuro. É a própria dúvida, acerca da existência do mundo exterior e das verdades racionais, que desemboca na primeira certeza. O cogito será a rocha inabalável, capaz de suportar o novo edifício do saber: "Penso, logo existo". (HUISMAN, 2000, p. 138)

Já na referida obra o autor começou a desenvolver sua metafísica propriamente dita. A verdade indubitável do cogito evidenciou a distinção entre corpo e alma. A alma trata-se de uma substância pensante, diferente do corpo. Toda a essência, para ele, está em pensar. Ao mesmo tempo, o Discurso do método instituiu os fundamentos da ciência nascente.

Com a hipótese do gênio maligno, Descartes conseguiu colocar em perigo o conhecimento sobre a existência do mundo exterior. Por esse viés, ele chegou à dúvida hiperbólica, isto é, ao questionamento relacionado ao conhecimento de todos os domínios do mundo exterior. Consoante tal argumento, é avençada a hipótese de um gênio, de natureza maldosa, que estivesse a todo tempo distorcendo ou comandando os nossos sentidos e os nossos critérios de percepção. Assim, nenhuma certeza poderia ser afirmada, já que todas as coisas, o ar, a terra, os sons etc, poderiam tratar-se de meras fraudes ou ilusões.

A partir de um cenário desolador, qual seja, de que não há certeza sobre nada, o filósofo erigiu a única convicção capaz de prosperar:

\footnotetext{
Mas existe alguém, não sei quem, enganador muito poderoso e astucioso, que dedica todo o seu empenho em enganar-me sempre. Não há, então, dúvida alguma de que existo, se ele me engana; e, por mais que me engane, nunca poderá fazer com que eu nada seja, enquanto eu pensar ser alguma coisa. De maneira que, depois de haver pensado bastante nisto e analisado cuidadosamente todas as coisas, se faz necessário concluir e ter por inalterável que esta proposição, eu sou, eu existo, é obrigatoriamente verdadeira todas as vezes que a enuncio ou que a concebo em meu espírito. (DESCARTES, 2004b, p. 258)
}

Não há como duvidar de que, ao duvidar, estou pensando. Se existe pensamento, existe algo que pensa. E se penso, logo existo. Eis a proposição consagrada, a única certeza indubitável, a única capaz de superar o problema da existência do mundo exterior. 
Disso resulta que pensar justifica a existência da substância do tipo res cogitans. A substância é o que existe per si, sem necessitar de outra coisa. A res cogitans, coisa pensante, alma, espírito, subjetividade, consciência, todos sinônimos em linguagem cartesiana, uma vez que não depende de mais nada além de si, sequer de um lugar, e por si própria duvida, concebe, afirma, nega, ama etc, justifica a sua existência como substância, como aquilo que é por si. Assim, pensar é existir; deixar de pensar é deixar de existir. E como não tem extensão, ela pode existir sem o corpo (res extensa), sendo, portanto, imortal. Nesse sentido é que falamos, em Descartes, que o pensar justifica a existência de uma substância.

Também já dissemos anteriormente que, além das principais regras do método, o desígnio fundamental do filósofo francês consistiu em formular os fundamentos da metafísica, considerando que, a seu modo de ver, método e metafísica estão inextricavelmente associados.

Assim, com o famoso Cogito, ergo sum, René Descartes passou a influenciar decisivamente toda a filosofia posterior, todos os domínios da vida humana. Isso porque concebeu o homem, primeiramente, como ser pensante, e com isso estabeleceu uma metafísica da subjetividade. Sua premissa básica é a de que a única certeza indubitável é a existência de si mesmo. Corpo e alma, para ele, são duas substâncias diferentes, duas realidades que não se confundem: res extensa e res cogitans. Com esse dualismo, estipulou a primazia da razão para definir a nossa natureza. Qualquer objeto é definido como res extensa, exceto o homem, res cogitans, que é razão, alma, consciência, racionalidade pura.

O método cartesiano inaugurou a modernidade porque se apoiou unicamente nas forças racionais do homem. Com ele, o autor anunciou o pensamento moderno, inaugurou o domínio da certeza científica, da racionalidade:

[...] eis que imperceptivelmente cheguei aonde queria; porque, por ser coisa atualmente conhecida por mim que só concebemos os corpos por intermédio da capacidade de entender que há em nós e não por intermédio da imaginação nem dos sentidos, e que não os conhecemos pelo fato de os ver ou de tocá-los, mas apenas por concebê-los por meio do pensamento [...]. (DESCARTES, 2004b, p. 268)

Nessa senda, surgiu o movimento iluminista e a crença no método científico. O modelo matemático-cartesiano garantiria a racionalidade dos fenômenos naturais, a ciência como paradigma primordial e legítimo para fundamentar a existência do mundo. Esse estatuto científico-mecanicista, de confiança desmedida na razão, portanto, é o que vigora até hoje em nossa sociedade ocidental. O próprio Descartes referiu-se metaforicamente ao homem como 
uma máquina. E tal pensamento racionalista acerca do ser humano e do mundo é o que tomaremos, neste estudo, como a concepção cartesiana de homem.

Sobre essa concepção, Marques (1993, p. 37) afirma que

\begin{abstract}
Na conclusão de seu livro, Laporte [...] diz que, embora Descartes não desconheça o valor de certos movimentos irracionais da alma, é à razão que ele dá o primado. E por razão Descartes entende o conhecimento puro e simples, em seu estado puro provido da ideia clara e distinta. Laporte vai ainda mais além, quando diz que há um temperamento racionalista no homem que procura ser otimista em matéria de saber. 'Esse homem não hesita em suas pesquisas. Ele se lança, sem receio, a todos os postulados que lhe parecem úteis. Ele segue em frente, seguro de vencer as dificuldades ou seguro de que um outro as vencerá'. Temos aí todo o projeto que Descartes realizou. (grifos nossos)
\end{abstract}

Em epistemologia, costumamos definir o racionalismo, grosso modo, como um ponto de vista que privilegia a razão como forma de conhecimento, em oposição ao empirismo e ao criticismo. Descartes, ao certo, foi um dos principais representantes dessa vertente epistemológica, estribado fundamentalmente em esteio matemático. Nunca é demais sublinhar a grandeza inestimável da sua obra, que pretendeu fixar bases sólidas para o saber em meio a um ambiente cético, dominado pelo recurso à autoridade religiosa, que se sustentava, muitas vezes, em meros expedientes extramundanos de divinização do conhecimento.

Diante de tais observações, é preciso acautelarmo-nos também a respeito de um possível reducionismo apressado e empobrecedor em relação ao pensamento do filósofo francês. Ao designá-lo de racionalista não podemos resvalar no descuido discursivo de encerrar o ideário cartesiano num dogmatismo limitador e perfunctório. A perspectiva que se abriu com Descartes foi muito maior do que qualquer tentativa de rotulá-lo ou diminuí-lo. Trata-se sem dúvida de um clássico, “[...] cuja obra repercute já há três séculos. Sua filosofia une o velho e o novo, e seu resultado final permanece um desafio para toda a humanidade" (MARQUES, 1993, p. 9).

Dentro das nossas pretensões, por conseguinte, é preciso ficar claro que por concepção cartesiana de homem estamos tentando assentar um paradigma que se ancora na proeminência da razão estrita ou meramente instrumental para a interpretação do homem. Além disso, o dualismo espírito-corpo recebeu inúmeras críticas e precisou ser elucidado e reparado por Descartes e também por filósofos coevos seus, que procuraram uma conciliação mais evidente, sobretudo no aspecto substancialista. Os modelos dualistas, como o cartesiano, têm sido bastante questionados hoje em favor de concepções mais unitárias, integrais de homem. 
Em face disso, é indispensável esclarecermos que a interpretação antropológica cartesiana aqui tomada trata-se daquela mais tradicional, dualista, que entende o homem notadamente pela via da sua faculdade intelectiva, como uma entidade estritamente racional.

\section{Heidegger e o problema do ser}

Um dos traços distintivos do pensamento de Martin Heidegger (1889-1976) foi a reformulação da questão primordial do ser. Em suas especulações, o filósofo alemão recolocou com maestria esse questionamento, sustentando, por exemplo, que o homem moderno alienou-se do seu ser genuíno.

Em Ser e tempo, sua obra-prima, o autor tratou com originalidade a problemática do ser, no turbulento período entreguerras. A apresentação da obra justamente nesse cenário afigurou-se de modo bastante pertinente, posto que a vida moderna havia atingido o ápice do esgotamento. O contexto era de crise econômica, política, social, internacional. O contexto era de velamento absoluto do ser.

Nesse sentido, o ponto fulcral da reflexão heideggeriana vai mais além do que a ontologia antiga poderia supor. A tradição costuma definir o ser como o conceito mais geral e mais indeterminado. Para o alemão, via oposta, o sentido do ser não é vazio e indefinível, mas determinante ele mesmo da nossa compreensão de nós mesmos e do mundo. O legado clássico culminou destarte com o que o autor denominou de esquecimento do ser.

Isso significa dizer que a metafísica clássica, mormente a partir de Aristóteles, desviou-se da correta análise da questão do sentido do ser, já que enalteceu demasiadamente o mero estudo dos entes na sua substancialidade, ou melhor, o estudo de cada ente isolado um do outro, apenas de maneira hierárquica e ordenada. À medida que aprofundava no ente, com doutrinas cada vez mais refinadas, a tradição aristotélica também se afastava do ser em sua totalidade. O ser ficava disperso, velado nos entes.

Nesse sentido é que, para Heidegger, a história da metafísica é a história do esquecimento do ser. Os filósofos tomaram o ente no lugar do ser e isso trouxe consequências muito relevantes. Ao tomar o ente em vez do ser, a filosofia disseminou uma noção de ser puramente estática, vinculada ao presente, oposta à passagem do tempo. Ao engessar os entes em doutrinas e proposições a metafísica clássica deixou de pensar o ser à luz da questão temporal: o ser ficou isolado do tempo. Ao contrário, ao definir o ser do homem como 
Dasein, o filósofo alemão certamente o está definindo como uma estrutura temporal em que passado, presente e futuro se relacionam. O tempo é fundamental para a compreensão do ser do homem.

\title{
Heidegger assevera que
}

\begin{abstract}
Esse "tempo", porém, ainda não foi des-dobrado e des-envolvido em sua essencialização nem poderá sê-lo (no terreno e na perspectiva da "Física"). Pois, quando, no fim da Filosofia Grega, se introduziu com Aristóteles a reflexão sobre a essencialização do tempo, teve ele de ser tomado como algo, de algum modo, presente, ousia tis. É o que se exprime no fato de o tempo ter sido apreendido a partir do "agora", como o que cada vez e só está presente. O passado é o "não-maisagora". O Ser, no sentido do que é objetivamente dado (presença), subministrou a perspectiva para a determinação do tempo. E assim o tempo não chega a ser a perspectiva, que propriamente se seguiu na interpretação do Ser. (HEIDEGGER, 1966, pp. 294-295)
\end{abstract}

A análise de Heidegger apresenta alguns aspectos de notável interesse filosófico, uma vez que se constitui numa importante inovação sobre o conceito de tempo. $\mathrm{O}$ acesso ao ser, enquanto tal, somente se dá em concomitância com o elemento temporal. A verdade é sertempo. A diversidade manifestativa do ser é determinada pari passu com a temporalidade.

Por conseguinte, essa mudança de horizonte modal resultou também em uma mudança significativa acerca da interpretação do futuro. O caráter estabilista do tempo foi rechaçado em benefício de uma interpretação temporal voltada para a estrutura do possível. Apesar da finitude, o Dasein é capaz de projetar-se no futuro, como possibilidade, sendo a morte justamente a possibilidade derradeira. Isso quer dizer que o futuro recebe nova hermenêutica, pois o tempo (passado, presente e futuro) passa a ser tratado como horizonte transcendental da questão do ser. Em outras palavras,

\footnotetext{
A temporalidade originária e própria temporaliza-se a partir do porvir em sentido próprio, de tal modo que só porvindouramente sendo o ter-sido é que ela desperta a atualidade. O porvir é o fenômeno primário da temporalidade originária e própria. De acordo com a primazia do porvir, a temporalização modificada ainda há de se transformar, apesar de aparecer no "tempo" derivado. (HEIDEGGER, 2014, § 330, p. 414)
}

O homem assim é poder-ser, isto é, tem em si mesmo a sua possibilidade mais autêntica, o seu ser enquanto tal no próprio processo de estar-sendo. Para Vattimo (1996, p. 24), “esta idéia do homem como poder-ser [...] orientará substancialmente todo o desenvolvimento de Ser e tempo". O tratamento dado ao homem por Heidegger é o de uma estrutura de possibilidades. A possibilidade, diz ainda Vattimo (1996, p. 24), “[...] é, com efeito, o próprio sentido do conceito da existência". O caráter mais geral do homem, sua 
natureza própria, é existir enquanto possível. Isso significa uma visível contradição concernente à natureza clássica do ser dos entes, sempre constante, pois poder-ser significa não ter uma essência perene, uma natureza invariável, permanentemente característica de si, ao menos à maneira antiga.

Em virtude disso, nessa nova perspectiva temporal o futuro passou a receber nova hermenêutica, a ocupar lugar determinante no entendimento da compreensão de homem. $\mathrm{O}$ porvir foi levado às últimas consequências para o desvelamento do ser. Esse ponto de vista, obviamente, coloca em xeque o conceito clássico da realidade como mera presença.

Mas antes de avançarmos um pouco mais na discussão, somos levados, primeiramente, a tratar das principais concepções filosóficas a respeito do tempo. Depois disso, será possível compararmos com mais sobriedade os dois paradigmas de homem e tempo aqui suscitados, com as suas devidas conexões. Passemos às principais linhas de pensamento a respeito do tempo em filosofia.

\section{A questão filosófica do tempo}

A questão filosófica do tempo, evidentemente, vai um pouco além daquilo que o senso comum poderia imaginar. Cotidianamente, o tempo é a sucessão permanente de eventos que gera em nós as noções de passado, presente e futuro. Todos somos capazes de perceber a passagem das horas, dos dias, dos anos, o caráter continuísta da vida.

No geral, segundo Abbagnano (2000, p. 944), podemos distinguir três concepções fundamentais sobre o tempo:

(1) o tempo como ordem mensurável do movimento; (2) o tempo como movimento intuído; (3) o tempo como estrutura de possibilidades. À primeira concepção vinculam-se, na Antiguidade, o conceito cíclico do mundo e da vida do homem (metempsicose) e, na época moderna, o conceito científico de tempo. À segunda concepção vincula-se o conceito de consciência, com a qual o tempo é identificado. A terceira concepção, derivada da filosofia existencialista, apresenta algumas inovações na análise do conceito de tempo.

A primeira concepção considera-o como ordem mensurável do movimento e é o ponto de vista associado tanto com o espírito científico quanto com o conhecimento do senso comum. O tempo é a medida do movimento, sua delimitação, sua datação. É o conceito científico-mecanicista, atrelado à época moderna. Conseguintemente, trata-se da 
compreensão temporal vigente no senso comum: a sucessão contínua de eventos que produz em nós as ideias de passado, presente e futuro. Essa noção, enquanto causalidade, ocupou a reflexão de Aristóteles e de outros filósofos, na esteira dos quais se apoiou o pensamento cartesiano, ao considerar o tempo como número do movimento.

A segunda concepção toma o tempo enquanto movimento intuído e o vincula à consciência. O primeiro pensador a estreitar esses laços foi Plotino, tendo em Santo Agostinho o principal disseminador da doutrina. Hegel, de certo modo, também efetuou a ligação do tempo com a consciência, embora com apenas alguns aspectos dela. Mais modernamente, Bergson continuou a desenvolver tal relação, mormente ao tentar contrapor o tempo da vida, duração, com o conceito científico de tempo. Além deles, também Husserl discorreu sobre o tempo fenomenológico, a consciência, como corrente infinita de vivências. Precisa ficar claro que, nesta concepção de tempo, de devir intuído, os filósofos o compreendem notadamente em relação ao tempo presente, porque a consciência é sempre um agora.

A terceira concepção procurou transformar o tempo em estrutura da possibilidade, eis a grande inovação. Ao expor sua teoria sobre ato e potência, Aristóteles já se notabilizava como o primeiro grande pensador do possível, ao preconizar uma perspectiva dinâmica do ser. Contudo, o entendimento aristotélico acabou relacionando-se mais estreitamente com um paradigma necessitarista e atualista do ser, atrelado ao necessário e atual, que obviamente foi o que se comunicou à ciência moderna.

Pela perspectiva do tempo enquanto estrutura da possibilidade, o ser se determina como tempo possível. A possibilidade transforma-se no sentido mesmo do ser. $\mathrm{O}$ traço mais distintivo do homem é precisamente o existir na qualidade de possível. Sem dúvida Martin Heidegger foi o principal representante dessa vertente, enfrentando a relação ser-tempo na sua mais profunda amplitude, não apenas como simples presença.

De modo genérico, são essas as três principais concepções filosóficas acerca do tempo. $\mathrm{Na}$ presente investigação, interessa-nos abordar tanto a primeira como a terceira. É chegado, pois, o momento de arrazoar sobre essas duas perspectivas, bem como suas implicações mais imediatas para a compreensão de homem. 


\section{A compreensão de homem e a questão do tempo futuro a partir de Descartes e} Heidegger

A ciência e o modelo cartesiano de razão instrumental acabaram afastando o homem contemporâneo das suas estruturas ético-ontológicas mais elementares. O homem-indivíduo ficou fragmentado, desnaturalizado, diluído na racionalização da existência. Esse é o contexto da história do esquecimento do ser, tão propalado por Martin Heidegger.

Em outras palavras, isso significa que a modernidade, que trouxe em seu bojo o império do método e a supremacia deste em relação às coisas, acabou alijando-se do mundo da vida onde, afinal, o homem permanece a ser, a viver, a compreender. O saber para fazer (ciência) camuflou o saber como fim em si mesmo ou saber prático (filosofia, ética, virtude etc). Desde a modernidade, com Descartes, a objetividade das ciências experimentais, que se impôs como modelo único de saber, acabou contaminando o homem e a própria filosofia.

À luz dessas considerações, podemos perceber que existe uma discrepância fundamental entres os modelos sustentados por Descartes e Heidegger. A leitura heideggeriana de Descartes é a leitura que o filósofo alemão empreende acerca da sociedade e do homem hodierno: o homem científico-mecanicista, afastado de si mesmo. Ao contrário, Heidegger enfatiza que o homem é ser-no-mundo, é Dasein. É preciso, assim, repensar essa relação homem-mundo a partir de uma aproximação com a questão primordial, a questão do ser. Temos que voltar às coisas mesmas, diria Husserl.

Ora, se Descartes foi uma resposta ao ceticismo, então Heidegger representa uma resposta ao racionalismo. A grande preocupação heideggeriana foi ontológica, e não epistemológica. A razão virou inimiga, por assim dizer, do próprio pensamento, pois uma adequada compreensão de homem está além da razão estrita. Precisamos reter, de Heidegger, que há uma mudança de foco e uma tentativa de explicar o homem a partir da sua própria existência no mundo.

Mais especificamente em relação ao tempo, uma das grandes diferenças entre a visão cartesiana e a visão ventilada por Heidegger é justamente o fato de a primeira interpretar o tempo mecanicamente, como uma sucessão de eventos com um fim definido, à medida que a segunda passa a abordá-lo como uma estrutura de possibilidades, como uma estrutura de projeção: “[...] o tempo é originariamente o por-vir (Zu-kunft)" (ABBAGNANO, 2000, p. 947). 
Isso significa dizer que o filósofo germânico concebeu o tempo como possibilidade, não mais como necessidade. $\mathrm{O}$ tempo transformou-se na eventualidade de diversas ordens $\mathrm{e}$ deixou de ser uma cadeia causal. Passou a representar uma estrutura contingente, e não mais necessária.

Abbagnano (2000, p. 948) indica, ademais, que "o passado pode ser entendido como ponto de partida ou fundamento das possibilidades porvindouras, e o futuro como possibilidade de conservação ou de mudança do passado, em limites (e aproximações) determináveis". Poderíamos dizer, numa linguagem existencialista, que o homem é capaz de dispor do futuro, projetar-se nele como ser dotado de autenticidade. Os determinismos dão lugar às liberdades. A introdução de novos conceitos interpretativos, “[...] expressos por termos como projeto ou projeção, antecipação, expectativa, etc., mostraram-se úteis nas análises filosóficas e passaram a fazer parte do uso filosófico corrente" (ABBAGNANO, 2000, p. 948).

Assim posto o assunto, podemos facilmente perceber a contraposição entre dois paradigmas possivelmente inconciliáveis. Por um lado, a concepção racionalista de Descartes produziu a interpretação mecânica do tempo, ou seja, um contínuo de eventos com rumo definido, a ordem mensurável do movimento. Por outro, o tempo enquanto estrutura possível, contingente, como projeção. Nesse sentido, podemos falar do anticartesianismo presente no pensamento do autor de Ser e tempo.

No entender de Blanc (2011, p. 125),

Nos mais diversos ramos das ciências da natureza desenha-se, além disso, neste último quartel de século, o estertor definitivo do paradigma mecanicista, que vigorou na modernidade e tão grandes malefícios trouxe à ontologia, obrigando-a a um mais ou menos confesso dualismo substancial. Na verdade, como poderia comportar uma matéria, determinada por leis necessárias, a possibilidade e o acontecimento, em que se inscreve a aventura escalonante da vida?

Em Descartes, a certeza indubitável do cogito fundamenta metafisicamente o conhecimento futuro. Existe um conhecimento infalível, originário, que pretende amparar e solidificar as certezas porvindouras. O tempo é uma cadeia de eventos que se funda no momento presente. Dito de outro modo, o tempo é uma "[...] totalidade presente porque toda ordem pressupõe a simultaneidade de suas partes, de cuja recíproca adaptação ela nasce" (ABBAGNANO, 2000, p. 947). 
Com Heidegger, existe uma alteração significativa dessa lógica, já que, consoante Abbagnano (2000, p. 947), “a primeira característica dessa concepção é o primado do futuro na interpretação do tempo". O ser humano constitui-se de uma estrutura tríplice: passado, presente e futuro. O ser, pois, é tempo, e o tempo é o ser. Diferente da concepção clássica, essa estrutura é inseparável, é uma coisa só.

A consciência fornece ao homem a prerrogativa de conhecer o mundo e, portanto, modificá-lo intencionalmente. Ele é o único dos seres possuidor da capacidade projetante, apto a autodeterminar-se conforme um planejamento. A verdadeira existência é a possibilidade de transcender aquilo que somos: eis a natureza do ser do homem. $\mathrm{O}$ fundamento da existência humana é o futuro, a perspectiva, o projeto que se concebe. Para os existencialistas, o que somos inclui principalmente aquilo que esperamos.

Nessa senda, Capra (1975, p. 25) alude que

\begin{abstract}
A filosofia de Descartes [...] exerce, até hoje, uma tremenda influência sobre o modo de pensar ocidental. A famosa frase cartesiana Cogito ergo sum ("penso, logo existo") tem levado o homem ocidental a igualar sua identidade apenas à sua mente, em vez de igualá-la a todo o seu organismo. [...] A mente foi separada do corpo, recebendo a inútil tarefa de controlá-lo, causando assim um conflito aparente entre a vontade consciente e os instintos involuntários. Posteriormente, cada indivíduo foi dividido num grande número de compartimentos isolados de acordo com as atividades que exerce, seu talento, seus sentimentos, suas crenças etc [...].
\end{abstract}

Com efeito, o espírito científico apresenta-nos - isso não é novo - uma visão de mundo fragmentada, uma visão que busca conhecer a vida acima de tudo, de todos, dizendo atuar sob o mote do real, do verdadeiro, e desse modo acaba cometendo excessos, subvertendo a existência, esterilizando o ser. Essa razão unidimensional, estritamente técnica, representa, para Heidegger, o grande perigo para a humanidade futura, isso porque " [...] a visão técnica do mundo [...] tende a monopolizar as outras formas de ser no mundo, além de consistir em um modo de desligamento do homem com relação à natureza" (TARGA, 2014, p. 79). A filosofia heideggeriana estabelece uma dura crítica ao excesso de racionalismo da sociedade ocidental, cujos ícones máximos são a ciência e a tecnologia. E, ao fazê-lo, certamente deixa transparecer um ponto de vista mais sistêmico, integral, holístico.

Como estrutura de possibilidade, o homem então deixa de ser considerado como uma substância dada, fixa, imutável, e passa a ser concebido como algo a fazer-se, em permanente transformação, que deve superar-se e triunfar sobre si mesmo. O homem é algo a ser superado, já falava Nietzsche. O futuro não é resultância trivial do presente e tampouco do 
passado. Pelo contrário, o futuro é motor do presente na proporção em que aponta e impulsiona a disposição e o fundamento da atualidade.

\section{Conclusão}

Ainda que não possamos prever o amanhã, é muito importante a questão aqui formulada. O tempo é uma categoria filosófica urgente. Se a filosofia, por si só, já é um conhecimento especulativo, falar sobre o futuro pode ser um conhecimento especulativo ainda maior. No senso comum, todos são capazes de perceber a ocorrência de eventos, a incontornabilidade do tempo, que passa, que coloca umidade nas paredes e cabelos brancos nos homens, diria Fernando Pessoa.

O futuro é uma premissa obrigatória para que as sociedades tenham sentido de direção. O amanhã é condição necessária para que a humanidade possa orientar-se. Decerto é imprescindível considerarmos o porvir em sede de qualquer pretensão antecipativa. Uma constatação que pouco exige do nosso raciocínio é a de que, no ocidente, temos vivido um modelo civilizatório agonizante. Por outro lado, também é fácil percebermos que o pensamento orgânico, sistêmico, integral, parece preocupar-se mais com o tempo futuro, com o homem, o universo.

O ente é a realidade particularizada, empírica, onde a vida encontra-se imiscuída. O homem é o único ente capaz de questionar-se sobre o seu ser. Mas o homem é o único ser que é ser-aí, ser-no-mundo, Dasein, ou seja, o único que se questiona ao mesmo tempo em que é.

Heidegger, ao interpelar o ser, sem dúvida está pretendendo uma indagação totalizante, transdisciplinar. Se a filosofia é, por excelência, o ramo do conhecimento que inicia pelas perguntas, o filósofo alemão procurou recolocar uma pergunta ainda mais fundamental, um questionamento que antecede a qualquer outro. Um questionamento que procura transcender o paradigma de racionalidade dominante, ultraespecializado, fragmentário, distorcido. Trata-se de um modelo cada vez mais debatido, questionado, obsoleto.

Por esse prisma podemos aduzir, outrossim, um componente ético em nosso viver neste mundo, conquanto o pensamento heideggeriano não evidencie propriamente a análise da conduta moral dos homens em sociedade. $\mathrm{O}$ autor não aborda de maneira direta conceitos como regras, valores, vontade, liberdade, consciência, busca da felicidade etc. Ainda assim, "[...] a ética acenada em Ser e tempo é uma ética da finitude, ligada a uma hermenêutica do 
ser-aí [...] consiste em estar-aberto [...] trata-se de uma 'ética originária', uma ética do habitar no mundo-projeto" (SALES, 2002, p. 48).

Sobre a questão temporal, um dos problemas é que o projeto racionalista tende a considerar o tempo como uma grandeza subjetiva, relacionada à medição do movimento segundo o anterior e o posterior. Além disso, a epistemologia cartesiana separa não apenas a mente da matéria como também o sujeito do objeto.

Em Heidegger, por outro lado, existe unidade entre sujeito e objeto porque o homem é ser-no-mundo, e não fora dele. O homem só existe na situação fática, concreta, sendo impossível separá-los. E o tempo não é uma sequência de agoras, que passam em si, que emergem e desaparecem. O tempo deve ser considerado como dimensão objetiva e estruturante do real.

Do ponto de vista ontológico-existencial, a verdade absoluta cede lugar à possibilidade, ao poder-ser. O ser-ai assume a possibilidade do seu próprio futuro porque a estrutura do ente é um devir. O futuro é uma determinação inexorável do ser.

A esse respeito, Blanc (2011, p. 105-106) discorre que

\begin{abstract}
No acontecer temporal do futuro que devém e se torna passado, o presente vivido imaginativamente torna-se tempo criador, tempo em que o sonho da vida por viver suspende o peso da vida já vivida e amadurece até se converter em poder de começar. Aberto à dimensão da esperança, a imaginação tem assim a força inaugural de renovar a vida, o poder de refigurar o tempo, abrindo-o a potencialidades não efetivadas no passado.
\end{abstract}

Testemunhamos, hoje, uma inadequação cada vez maior entre os saberes fragmentados, compartimentalizados, filhos de Descartes, e as realidades multidimensionais, multifacetadas, complexas. Isso responde, de certa maneira, à pergunta Onde estamos? Mas qual o futuro? Para onde vamos? Urge a construção de um saber mais abrangente, com um nível de compreensão mais elevado, que se fundamente na própria vida.

O excesso de cientificismo da sociedade ocidental afastou o homem do mistério do ser e diminuiu a sua capacidade de se autoprojetar. Por outro lado, o filósofo de Ser e tempo pretendeu enaltecer o primado do futuro na interpretação do tempo presente. $\mathrm{O}$ fundamento da existência humana não é o agora, mas o tempo futuro. Eis a engenhosa inversão realizada por Heidegger: o que somos precisa ser pensado em função daquilo que seremos. Não é o presente que causa o futuro. Antes: é o futuro que causa o presente. Nós somos aquilo que esperamos. 


\section{REFERÊNCIAS BIBLIOGRÁFICAS}

ABBAGNANO, Nicola. Dicionário de Filosofia. Tradução de Alfredo Bosi. 4. ed. São Paulo: Martins Fontes, 2000.

BLANC, Mafalda de Faria. Introdução à Ontologia. 2. ed. Lisboa: Instituto Piaget, 2011.

CAPRA, Fritjof. O Tao da Física: um Paralelo entre a Física Moderna e o Misticismo Oriental. Tradução de José Fernandes Dias. São Paulo: Cultrix, 1975.

DESCARTES, René. Discurso do Método (1637). Tradução de Enrico Corvisieri. São Paulo: Nova Cultural, 2004a, p. 33-100. (Os Pensadores) 2004, p. 233-334b. (Os Pensadores)

HEIDEGGER, Martin. Introdução à Metafísica. Tradução de Emmanuel Carneiro Leão. Rio de Janeiro: Tempo Brasileiro, 1966.

2014.

. Ser e Tempo. Tradução de Márcia Sá Cavalcante Schuback. Petrópolis: Vozes,

HUISMAN, Denis. Dicionário de Obras Filosóficas. Tradução de Ivone Castilho Benedeti. São Paulo: Martins Fontes, 2000.

MARQUES, Jordino. Descartes e sua Concepção de Homem. São Paulo: Edições Loyola, 1993.

SALES, Marcela Barbosa Leite. A Questão da Dimensão Ética na Analítica Existencial Heideggeriana. Ágora Filosófica, Universidade Católica de Pernambuco, ano 2, n. 1, jan-jun 2002. Disponível em: < http://www.maxwell.vrac.puc-rio.br/5222/5222.PDF>. Acesso em: 28 de outubro de 2016.

TARGA, Dante Carvalho. Ciência e Sociedade: Livro Didático. Palhoça: UnisulVirtual, 2014.

VATTIMO, Gianni. Introdução a Heidegger. Tradução de João Gama. 10. ed. Lisboa: Instituto Piaget, 1996. 